\title{
Extraction and preliminary study of antibacterial compounds of three species of Aspergillus genus
}

\author{
Amina Bramki ${ }^{\mathrm{a}^{*}}$, Meriem Frahtia ${ }^{\mathrm{b}}$, Atef Jaouani ${ }^{\mathrm{c}}$, Laid Dahimat ${ }^{\mathrm{a}}$, Noreddine Kacem Chaouche ${ }^{\mathrm{a}}$ \\ ${ }^{a}$ Laboratory of Mycology, Biotechnology and Microbial Activity, University of Mentouri Brothers-Constantine, Algeria \\ ${ }^{b}$ Laboratory of Medical Analysis, Public Establishment of Local Health, Mila, Algeria \\ 'Laboratory of Microorganisms and Active Biomolecules, University of Tunis El Manar, Tunisia
}

Received 30th December 2018 / Accepted 1st March 2019

\begin{abstract}
In the interest of discovering new antibiotic molecules, the antibacterial activity of three fungal strains namely: Aspergillus quadrilineatus, Aspergillus niveus, and Aspergillus wentii isolated from particular ecosystems was sought against six bacterial strains including three with Gram-positive staining (Staphylococcus aureus, Bacillus subtilis, Enterococcus faecalis) and three with Gram-negative staining (Escherichia coli, Psendomonas aeruginosa, Klebsiella pneumoniae). The results of the agar cylinder technique highlighted that the three fungal strains showed a considerable antibacterial activity. In order to optimize the extraction conditions of the bioactive molecules, five solvents in different polarities were tested, of which chloroform turned out to be the best one. After the selection of this solvent, four culture media of different compositions were used in order to determine the most adequate medium for the production of antibacterial substances. The results revealed that Czapek-dox medium supplemented with yeast extract turned out to be the most favorable one for the production of bioactive molecules from both strains: $A$. quadrilineatus and $A$. nivens, while the most suitable medium for the $A$. wentii strain was Sabouraud. In addition, a study of the antibacterial effect of organic extracts by the Biolog micro-culture system was performed using a range of concentrations. The obtained results revealed that the extracts of the three fungal strains presented a remarkable activity with different concentrations and this, against all the tested bacterial strains. It was recorded only for the three used fungal species, the antibacterial activity was studied for the first time by the Biolog system.
\end{abstract}

Keywords: antibacterial activity, Aspergillus, bioactive molecules, Biolog

\section{INTRODUCTION}

The bacterial resistance to antibiotics is one of the most serious threats to global health today. Every day, new mechanisms of resistance emerge and spread on a global scale, compromising our ability to treat the most common infectious diseases (Azoun, 2016).

In front of this alarming situation, the appropriate use of antibiotics is absolutely necessary to extend the clinical validity of these molecules. However, the long-term solution to counteract microbial resistance is to develop or search for new molecules (Madigan and Martinko, 2007; Saisivam et al., 2008; Berger Savin, 2014). In the 1990s, the discovery of bioactive metabolites of microbial origin grew exponentially thanks to technological advances. Unfortunately, among the discovered metabolites, many are analogues of already known molecules, compounds with no antibiotic activity or even minor compounds. The invention of new innovative chemical families becomes scarce (Berdy, 2005). Faced with these emerging needs and multiresistant germs, the

*Author for correspondence: Amina Bramki, Laboratory of Mycology, Biotechnology and Microbial Activity, University of Mentouri BrothersConstantine, Algeria. Email - br_amina@yahoo.fr 
search of new molecules represents a need (Sharma et al., 2005) which cannot be filled either by: the extraction of new derivatives in mutants of listed strains, the realization of new semi-synthetic molecules from known structure, the synthesis of new derivatives or the obtaining of new substances produced by new bacterial or fungal species isolated from explored or less explored ecosystems (Kitouni, 2007). This last path that was adopted during our study.

In addition, fungi are among the best candidates for the production of biologically active secondary metabolites. This kind of microorganisms is responsible for the production of about $22 \%$ active molecules with antibacterial effect on an industrial scale (Atoui, 2006). In fact, the genera Aspergillus and Penicillium as well as the species of the order Monilliales constitute the most important reservoirs (Botton et al., 1990).

For this reason, we sought to study the antibacterial activity of Aspergillus genus fungal strains isolated from different ecosystems as producers of active metabolites against resistant bacteria for the purpose of using their bioactive molecules.

\section{MATERIALS AND METHODS}

Producing strains. Three strains of Aspergillus genus were used to evaluate their antibacterial activity: Aspergillus quadrilineatus (MH109538) isolated from the soil taken from an arid zone; Laghouat (located at $400 \mathrm{~km}$ south of Algiers), Aspergillus niveus (MH109544), and Aspergillus wentii (MH109545) isolated from a thermal soil in the region of Teleghma (located in north-eastern Algeria). It should be noted that isolation and identification steps of fungal strains have been detailed in another article (Bramki et al., 2017).

Demonstration of the antibacterial activity of fungal strains by the agar cylinder technique. The used microbial support was composed of six bacterial strains, four ATCC strains (American Type Culture Collection), which were: Staphylococcus aureus (ATCC 25923), Bacillus subtilis (ATCC 6633), Escherichia coli (ATCC, 25922), Pseudomonas aeruginosa (ATCC, 27853), and two clinical strains namely: Enterococcus faecalis and Klebsiella pneumoniae.

Antibacterial tests must be performed from young cultures (18 to $24 \mathrm{~h}$ ), in the exponential growth phase. The opacity of the bacterial suspensions in sterile physiological water was equivalent to 0.5 McFarland (a bacterial concentration estimated at $10^{6} \mathrm{CFU} / \mathrm{ml}$ ) (Cavalla and Eberlin, 1994).

The fungal strains were seeded on PDA medium (Potato Dextrose Agar). After 14 days of incubation at $28^{\circ} \mathrm{C}$, agar cylinders of $6 \mathrm{~mm}$ in diameter were removed and deposited on the surface of Mueller-Hinton medium previously seeded following the NCCLS technique (National Commitee for Clinical Laboratory Standard) by tested bacteria. The Petri dishes carrying the agar cylinders were placed at $4^{\circ} \mathrm{C}$ for $4 \mathrm{~h}$, to allow the diffusion of the bioactive substances elaborated by the fungal strains, then incubated at $37^{\circ} \mathrm{C}$ for 18 to 24 h (Tortorano et al., 1979; Gungi et al., 1983).

\section{Study of the antibacterial activity}

\section{Choice of the optimum solvent for the extraction of bioactive molecules}

Preparation of extracts. Five solvents of different polarities were tested separately; chloroform, hexane, methanol, butanol and ethyl acetate to extract bioactive substances (Loucif, 2011 ; Boughachiche, 2012). $500 \mathrm{ml}$ flasks, containing $100 \mathrm{ml}$ of PDB (Potato Dextrose Broth) culture medium, were inoculated with eight disks of a seven days aged culture for each strain. After 14 days of incubation at $28^{\circ} \mathrm{C}$ (static fermentation), an identical volume of the tested solvent $(100 \mathrm{ml})$ was added to each flask containing the fungal culture. The mixture was crushed using ultra turrax, then filtered on Whattman paper No. 1. The filtrate was transferred to a separatory funnel, then, the organic phase was concentrated by vacuum evaporation using a Rotavapor. (Gengan et al., 1999 ; Ghorri, 2015). Each fungal extract was dissolved in dimethylsulfoxide (DMSO) in order to obtain a concentration of $100 \mathrm{mg} / \mathrm{ml}$.

Discs technique. To evaluate the antibacterial activity of organic extracts, sterile discs of $6 \mathrm{~mm}$ 
in diameter prepared from Wattman paper No. 1, containing $10 \mu \mathrm{l}$ of organic extracts. After drying, the discs were carefully placed on Petri dishes containing Mueller-Hinton medium previously seeded by the tested bacteria. Before incubation at $37^{\circ} \mathrm{C}$, the dishes were left for $2 \mathrm{~h}$ at $4^{\circ} \mathrm{C}$ to allow the diffusion of the bioactive substances (Yamaç and Bilgili, 2006 ; Hazalin et al., 2009). Results' reading was done after 18 to $24 \mathrm{~h}$. Any growth of inhibition zone around discs, even of a small diameter, was considered a positive result.

\section{Choice of the optimum medium for the} production of bioactive substances. Four liquid culture media of different composition: PDB, Sabouraud, Czapek dox supplemented with $2.5 \mathrm{~g} / 1$ of yeast extract and MEB (Malt Extract Broth) recommended for the production of secondary metabolites were tested in order to determine the most adequate medium for the production of bioactive molecules. After a static fermentation of 14 days, an extraction of secondary metabolites with chloroform was performed. The preparation and the antibacterial activity test of the obtained extracts have been done as described previously (choice of the solvent) (Mathan et al., 2013). It should be noted that three repetitions were performed for each test, and the diameters of the inhibition zones were measured in millimeter.

\section{Study of the antibacterial activity of organic extracts by the micro-culture system (Biolog).} From a concentration of $100 \mathrm{mg} / \mathrm{ml}(100 \mathrm{mg}$ of extract in $1 \mathrm{ml}$ of DMSO solvent), a successive one-half dilutions have allowed to prepare a range of concentrations ranging from 100 to 1.56 $\mathrm{mg} / \mathrm{ml}$ (Harrar, 2012). The bacterial suspensions were prepared from cultures aged from 18 to 24 $\mathrm{h}$, and were calibrated using a Biolog turbidimeter to reach a final turbidity of $85 \% \mathrm{~T}$, then, a volume of $220 \mu \mathrm{l}$ of Mueller Hinton Broth (supplemented with $1 \%$ of «Biolog Redox Dye Mix F » for Gram-positive bacteria and «Biolog Redox Dye Mix A » for Gram-negative bacteria), $15 \mu$ l of the diluting extract and the same volume of the bacterial suspension were placed into each well of the microplate.

Both DMSO solvent and bacteria only were performed as negative and positive controls respectively were performed. The microplates were placed in an Omnilog incubator-reader for $24 \mathrm{~h}$ at $37^{\circ} \mathrm{C}$, and the phenotypic behavior was recorded by a CCD camera (Al-Bayati, 2008; Benslama, 2014; Ghorri, 2015).

Indeed, this test was confirmed by the disc technique on Mueller Hinton Agar, and the discs were impregnated with $15 \mu$ l of each extract.

\section{RESULTS AND DISCUSSION}

The demonstration of the antibacterial activity of fungal strains by the agar cylinder technique. The antagonism test by the agar cylinder technique showed the ability of the three fungal strains to produce molecules with antibacterial effect. In fact, the strongest inhibition zones were observed against $S$. aureus with diameters of $33.67 \mathrm{~mm}, 33 \mathrm{~mm}$, and 31.33 $\mathrm{mm}$ for the three fungal strains $A$. quadrilineatus, $A$. niveus, and $A$. wentii respectively. In contrast, $E$. faecalis showed a sensitivity only with $A$. quadrilineatus with a diameter of $20 \mathrm{~mm}$. On the other hand, no inhibition zone was observed with the four tested strains B. subtilis, E. coli, $P$. aeruginosa, and $K$. pneumoniae (Table 1$)$.

Table 1. Demonstration of the antibacterial activity of fungal strains by the agar cylinder technique.

\begin{tabular}{|c|c|c|c|}
\hline \multirow{2}{*}{ Strain } & \multicolumn{3}{|c|}{ Diameter of inhibition zones (mm) } \\
\hline & A. quadrilineatus & A. niveus & A. wentii \\
\hline S. aureus & $33.67 \pm 6.03$ & $33.00 \pm 2.65$ & $31.33 \pm 3.21$ \\
\hline B. subtilis & - & - & - \\
\hline E. faecalis & $20.00 \pm 2.00$ & - & - \\
\hline E. coli & - & - & - \\
\hline$P$. aeruginosa & - & - & - \\
\hline K. pneumoniae & - & - & - \\
\hline
\end{tabular}

* (-): Diameter of the inhibition zone $<6 \mathrm{~mm}$. 
Our results agreed with those of Irobi et al. in 2000 , whereby the $A$. quadrilineatus fungal strain has a considerable antibacterial effect against Gram-positive bacteria. Abdelaziz in 2006, also showed that Aspergillus fungal strains had a considerable antibacterial effect against the tested bacteria. However, Aspergillus species are known by their production of antibacterial substances (Maria et al., 2005, Madki et al., 2010). These biologically active secondary metabolites are synthesized at the end of growth (Attalah and Kacem-chaouche, 1992).

\section{Study of antibacterial activity}

Choice of the optimum solvent for the extraction of bioactive molecules. The obtained results from antibacterial test showed that all the organic extracts have an antibacterial activity on at least one of the tested bacteria, with the exception of hexane extract of $A$. quadrilineatus strain, and that the most significant effect was especially obtained from the chloroform extracts, followed by ethyl acetate and butanol (Figures 1, 2 , and 3).

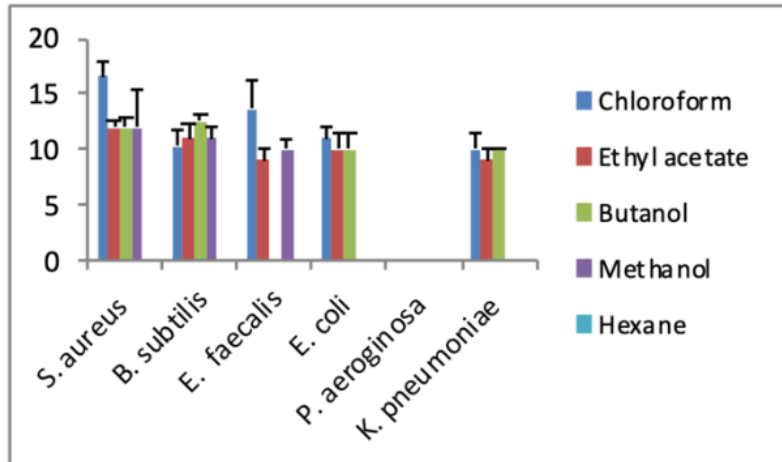

Figure 1. Antibacterial activity of organic extracts of the fungal strain $A$. quadrilineatus.

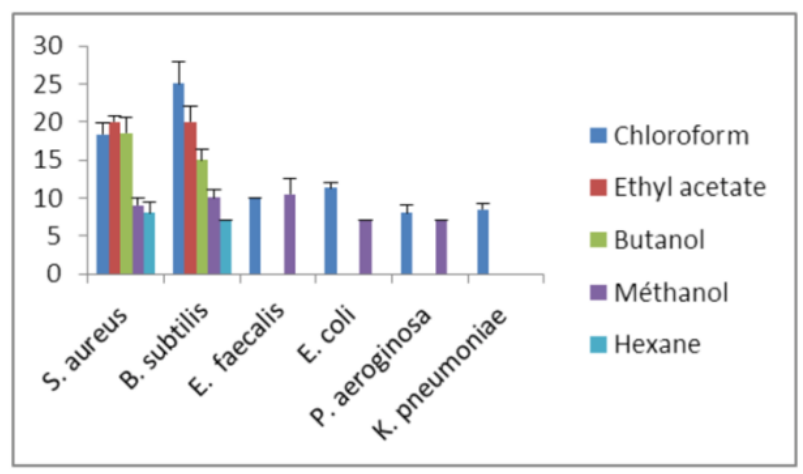

Figure 2. Antibacterial activity of organic extracts of the fungal strain $A$. niveus.

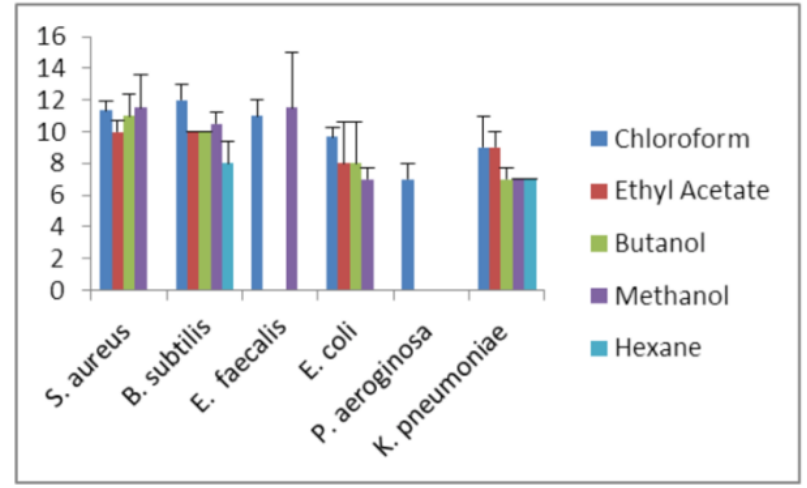

Figure 3. Antibacterial activity of organic extracts of the fungal strain $A$. wentii.

Regarding the chloroform extracts, considerable inhibition zones were observed by $A$. niveus strain extract against both $B$. subtilis and $S$. aureus with diameters of $25 \mathrm{~mm}$ and $18.33 \mathrm{~mm}$, in that order. As well as, $A$. quadrilineatus strain extract exhibited a remarkable effect on $S$. aureus bacterium with an inhibition zone of $16.67 \mathrm{~mm}$.

The same results were detected by ethyl acetate and butanol extracts of $A$. niveus fungal strain, where the average of inhibition zones' diameters ranged from $15 \mathrm{~mm}$ to $20 \mathrm{~mm}$ against the same bacterial strains: B. subtilis and S. aureus.

These results revealed that the chloroform was the best solvent for the extraction of fungal metabolites, especially that have an antibacterial effect, is in agreement with the results of Kitouni's and Loucifs results in 2007 and 2011, successively, who found that chloroform is among the best solvents used for the extraction of bioactive molecules. However, this solvent is often used for the extraction of secondary metabolites (Kosalec et al., 2004; Abdelaziz, 2006, Praveena and Padmini, 2011).

The appearance of the antibacterial activity by polar solvents (methanol and butanol), solvents of intermediate polarity (chloroform and ethyl acetate) and another non-polar (hexane), assumes that it is either several molecules of different polarity (each soluble in a different solvent) or one or more molecules soluble in various solvents. This last hypothesis is more probable since, according to Guernet and Hamon (1981), antibiotics' structure is generally complex, containing polar and non-polar characters, resulting in an affinity for very diverse solvents. 
Choice of the optimum medium for the production of bioactive substances. The antibacterial effect test of each fungal strain showed that the diameters of the inhibition zones vary from one culture medium to another and from one tested bacterium to another.

For the $A$. quadrilineatus fungal strain, the represented results in Figure 4 showed that the most important zones of inhibition were obtained by the disks impregnated with molecules from Czapek-dox medium, with diameters of $17.67 \mathrm{~mm}$ against $S$. aureus bacterium and $15 \mathrm{~mm}$ against $E$. faecalis bacterium, followed by the PDB medium with diameters of $16.67 \mathrm{~mm}$ and $13.67 \mathrm{~mm}$ against the bacteria $S$. aureus and E. faecalis, respectively.

Regarding the $A$. niveus fungal strain, the results in Figure 5 proved Czapek-dox medium as the most suitable medium for the production of antibacterial metabolites, followed by the PDB medium, in which the highest diameters against the two bacterial strains $B$. subtilis and $S$. aureus were shown.

In effect, Czapek-dox liquid medium supplemented with yeast extract was chosen as a specific medium for optimal production of secondary metabolites (Pamel et al., 2010). In addition, this medium contains yeast extract and sodium nitrate, which are good sources of nitrogen, adequate for the production of antibiotics; it also contains sucrose as a carbon source as well as mineral salts (Pandey et al., 2005).

However, the extract of the $A$. wentii fungal strain, coming from Sabouraud medium, reacted differently compared to other media, giving more distinct results. Moreover, considerable zones of inhibition: $24.33 \mathrm{~mm}, 20.33 \mathrm{~mm}$, and $18.67 \mathrm{~mm}$ in diameter were observed against the three bacterial strains: S. aureus, B. subtilis, and E. faecalis, respectively (Figure 6).

The best performance of Sabouraud's medium compared to other media can be explained by the presence of peptone, which is a source difficultly metabolized and therefore favors the production of antibiotics (Voelker and Altaba, 2001).

Several studies have shown that the nature of carbon, nitrogen, and the mineral sources of culture media influences enormously the production capacity of antibiotics in fungi. Furthermore, Boussaber et al. in 2012, showed that the antibacterial activity of the actinomycete strains depends mainly on the tested bacteria and the composition of the culture media.

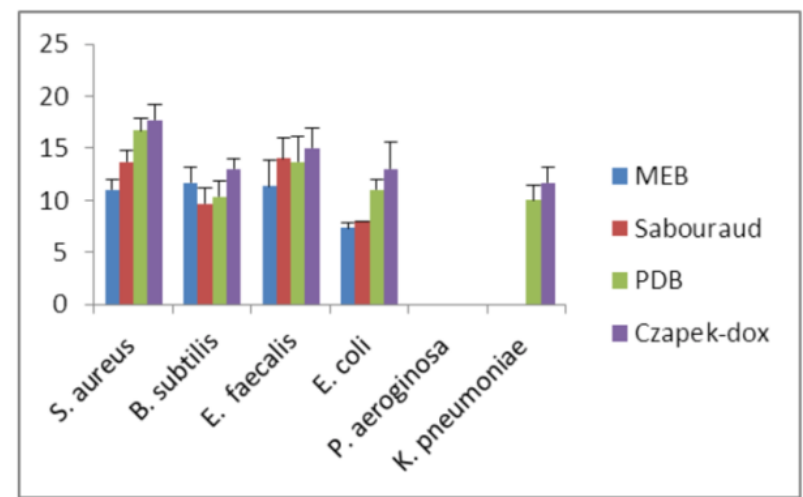

Figure 4. Effect of different culture media on antibacterial activity of the fungal strain $A$. quadrilineatus.

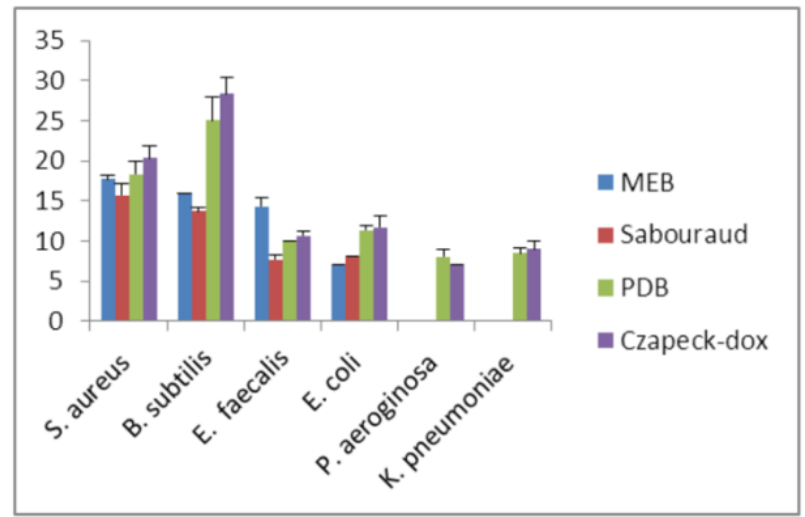

Figure 5. Effect of different culture media on antibacterial activity of the fungal strain $A$. niveus.

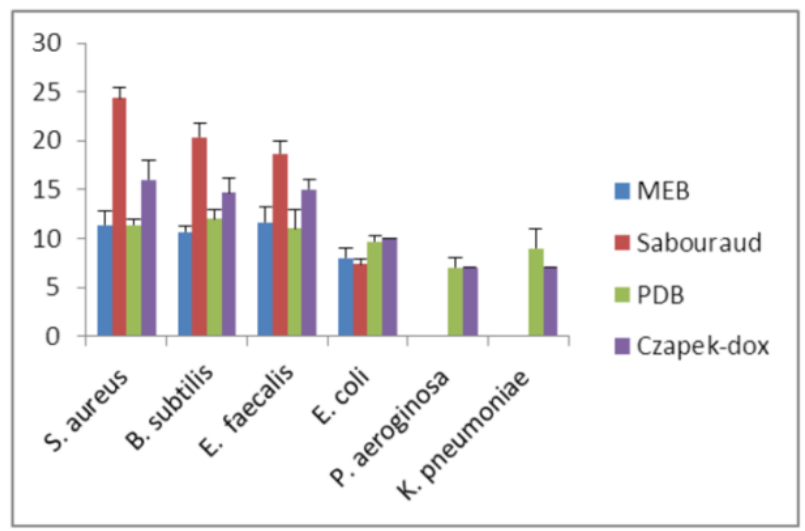

Figure 6. Effect of different culture media on antibacterial activity of the fungal strain $A$. wentii.

Study of the antibacterial activity of organic extracts by the micro-culture system (Biolog).

The study of the antibacterial effect of organic extracts by the Biolog micro-culture system revealed that the extracts of the three fungal 
strains presented a remarkable activity with different concentrations, against all the tested bacteria.

The results in Figures 7, 9, and 11 showed that the chloroformic solubilized extracts in DMSO with the concentrations 100,50 , and $25 \mathrm{mg} / \mathrm{ml}$ could almost inhibit the total development of the tested bacterial cells, unlike positive control (bacteria only) and negative control (DMSO + bacteria) that demonstrated a good development in wells.

Otherwise, the results mentioned in Figures 8, 10 , and 12 corresponding to the concentrations of the extracts ranged from 12.5 to $1.56 \mathrm{mg} / \mathrm{ml}$, indicated a diminution in the antibacterial effect during the decrease of the extracts' concentrations with all the tested bacteria.

However, the antagonism test performed by the discs imbibed with the fungal extracts confirmed the Biolog test (Tables 2, 3, and 4).

In regards to the tested germs, Gram-positive bacteria appear to be more sensitive to the bioactive molecules of the three fungal strains in comparison with Gram-negative bacteria. This is related to the results obtained by Hasavada et al. (2006), Atta et al. (2009), and Prabavathy and Nachiyar (2012). These results can be explained by the fact that these two groups of microorganisms differ morphologically (Kumara et al., 2010).

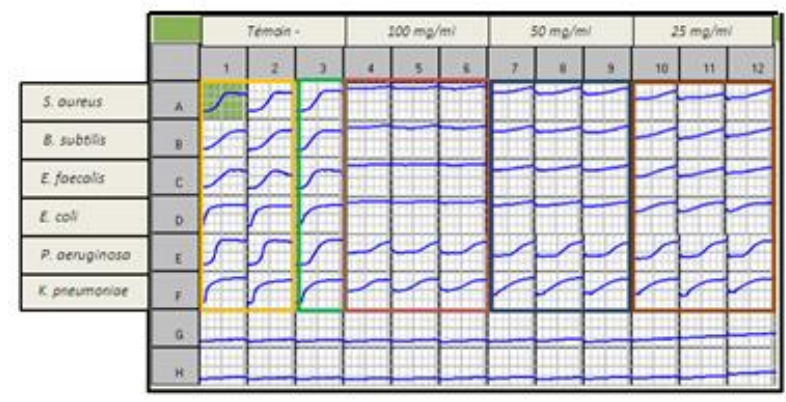

Figure 7. Kinetics of bacterial cell development. Antibacterial effect of chloroformic extract of $A$. quadrilineatus strain with different concentrations. 1-2: test bacteria (2 repetitions); 3: the bacterium with DMSO; 4-12: the different concentrations (from 100 to $25 \mathrm{mg} / \mathrm{ml}$ ); A-F: the different bacterial strains.

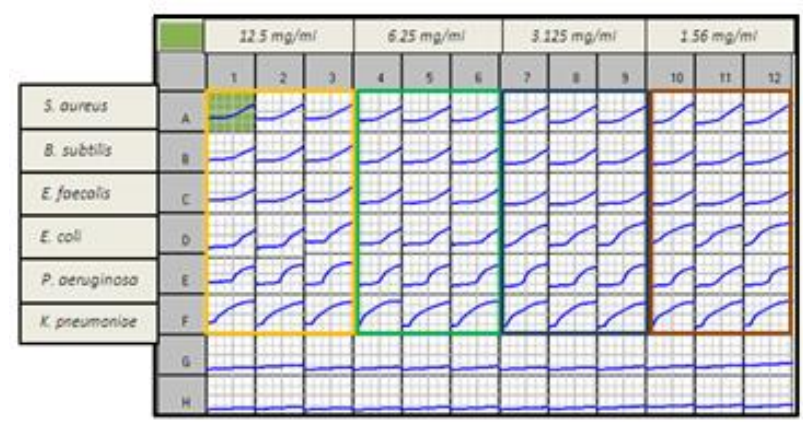

Figure 8. Kinetics of bacterial cell development. Antibacterial effect of chloroformic extract of $A$. quadrilineatus strain. 1-12: the different concentrations (from 12.5 to $1.56 \mathrm{mg} / \mathrm{ml}$ ); A-F: the different bacterial strains.

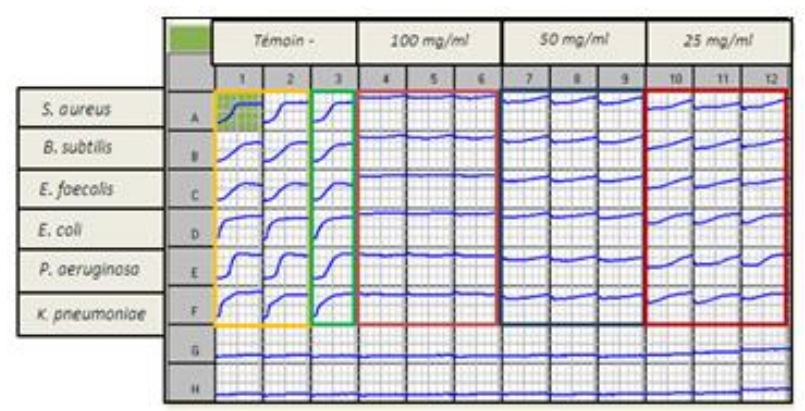

Figure 9. Kinetics of bacterial cell development. Antibacterial effect of chloroformic extract of $A$. niveus strain with different concentrations. 1-2: test bacteria (2 repetitions); 3: the bacterium with DMSO; 4-12: the different concentrations (from 100 to $25 \mathrm{mg} / \mathrm{ml}$ ); A-F: the different bacterial strains.

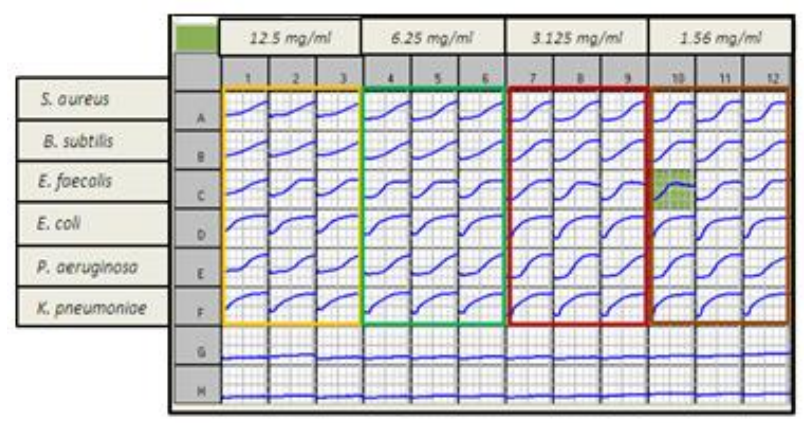

Figure 10. Kinetics of bacterial cell development. Antibacterial effect of chloroformic extract of $A$. niveus strain. 1-12: the different concentrations (from 12.5 to $1.56 \mathrm{mg} / \mathrm{ml}$ ); A-F: the different bacterial strains. 


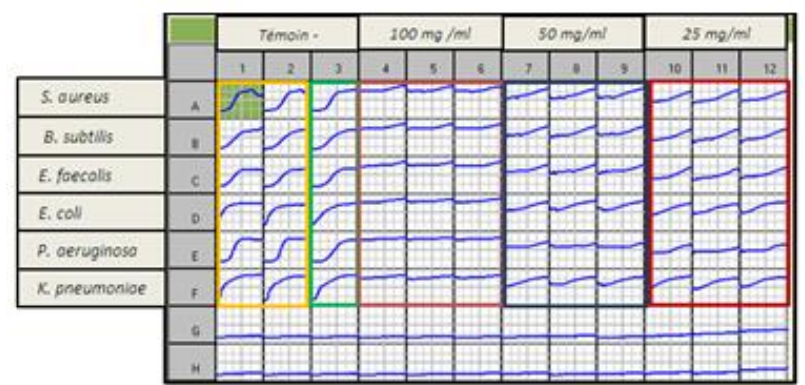

Figure 11. Kinetics of bacterial cell development. Antibacterial effect of chloroformic extract of $A$. wentii strain with different concentrations. 1-2: test bacteria (2 repetitions); 3: the bacterium with DMSO; 4-12: the different concentrations (from 100 to $25 \mathrm{mg} / \mathrm{ml})$; A-F: the different bacterial strains.

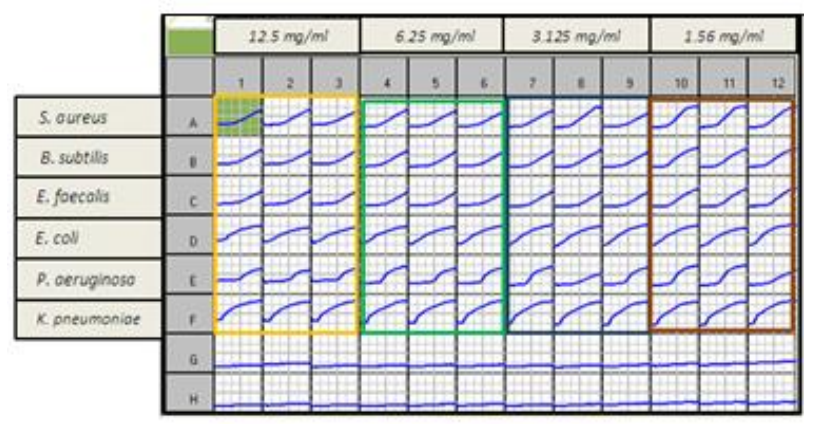

Figure 12. Kinetics of bacterial cell development. Antibacterial effect of chloroformic extract of $A$. wentii strain. 1-12: the different concentrations (from 12.5 to $1.56 \mathrm{mg} / \mathrm{ml}$ ); A-F: the different bacterial strains.

Table 2. Effect of different concentrations of chloroformic extract of $A$. quadrilineatus fungal strain on the test bacteria.

\begin{tabular}{lccccccc}
\hline \multicolumn{1}{c}{ Bacteria } & $\begin{array}{c}\mathbf{1 0 0} \\
\mathbf{m g} / \mathbf{m l}\end{array}$ & $\mathbf{5 0} \mathbf{~} \mathbf{g} / \mathbf{m l}$ & $\mathbf{2 5} \mathbf{~ m g / m l}$ & $\begin{array}{c}\mathbf{1 2 . 5} \\
\mathbf{m g} / \mathbf{m l}\end{array}$ & $\begin{array}{c}\mathbf{6 . 2 5} \\
\mathbf{m g} / \mathbf{m l}\end{array}$ & $\begin{array}{c}\mathbf{3 . 1 2 5} \\
\mathbf{m g} / \mathbf{m l}\end{array}$ & $\begin{array}{c}\mathbf{1 . 5 6} \\
\mathbf{m g} / \mathbf{m l}\end{array}$ \\
\hline $\boldsymbol{S . ~ a u r e u s}$ & $17.00 \pm 1.41$ & $14.00 \pm 0.00$ & $12.50 \pm 0.71$ & $10.50 \pm 0.71$ & $9.00 \pm 0.00$ & $8.00 \pm 0.00$ & $7.00 \pm 0.00$ \\
$\boldsymbol{B}$. subtilis & $14.00 \pm 1.41$ & $12.50 \pm 0.71$ & $11.33 \pm 0.58$ & $11.00 \pm 0.00$ & $10.00 \pm 0.00$ & $9.50 \pm 0.71$ & $8.00 \pm 0.00$ \\
$\boldsymbol{E}$ faecalis & $14.50 \pm 2.12$ & $12.50 \pm 0.71$ & $12.00 \pm 0.00$ & $11.50 \pm 0.71$ & $11.00 \pm 0.00$ & $10.00 \pm 0.00$ & $9.33 \pm 0.58$ \\
$\boldsymbol{E}$. coli & $15.50 \pm 0.71$ & $15.00 \pm 0.00$ & $13.50 \pm 0.71$ & $13.00 \pm 1.41$ & $10.00 \pm 0.00$ & $9.33 \pm 0.58$ & $8.50 \pm 0.71$ \\
$\boldsymbol{P}$. aeruginosa & $9.50 \pm 0.71$ & $8.33 \pm 0.58$ & $7.00 \pm 0.00$ & - & - & - & - \\
$\boldsymbol{K}$. penumoniae & $10.00 \pm 1.41$ & $9.50 \pm 0.71$ & $9.33 \pm 0.58$ & $8.00 \pm 0.00$ & $8.00 \pm 0.00$ & $8.00 \pm 0.00$ & $7.00 \pm 0.00$ \\
\hline
\end{tabular}

*(-): Diameter of inhibition zone $\leq 6 \mathrm{~mm}$

Table 3. Effect of different concentrations of chloroformic extract of $A$. niveus fungal strain on the test bacteria.

\begin{tabular}{lccccccc}
\hline \multicolumn{1}{c}{ Bacteria } & $\mathbf{1 0 0}$ & $\mathbf{5 0} \mathbf{~ g /} / \mathbf{m l}$ & $\mathbf{2 5} \mathbf{~ m g / m l}$ & $\begin{array}{c}\mathbf{1 2 . 5} \\
\mathbf{m g} / \mathbf{m l}\end{array}$ & $\begin{array}{c}\mathbf{6 . 2 5} \\
\mathbf{m g} / \mathbf{m l}\end{array}$ & $\begin{array}{c}\mathbf{3 . 1 2 5} \\
\mathbf{m g} / \mathbf{m l}\end{array}$ & $\begin{array}{c}\mathbf{1 . 5 6} \\
\mathbf{m g} / \mathbf{m l}\end{array}$ \\
\hline S. aureus & $19.00 \pm 1.41$ & $14.00 \pm 1.41$ & $12.50 \pm 0.71$ & $8.50 \pm 0.71$ & $8.00 \pm 0.00$ & $7.50 \pm 0.71$ & $7.00 \pm 0.00$ \\
B. subtilis & $26.50 \pm 2.12$ & $17.50 \pm 0.71$ & $14.00 \pm 1.41$ & $10.50 \pm 0.71$ & $9.50 \pm 0.71$ & $8.00 \pm 0.00$ & $7.50 \pm 0.71$ \\
E. faecalis & $16.50 \pm 0.71$ & $13.50 \pm 0.71$ & $12.00 \pm 0.00$ & $11.00 \pm 0.00$ & $9.33 \pm 0.58$ & $9.00 \pm 0.00$ & $8.00 \pm 0.00$ \\
E. coli & $13.00 \pm 1.41$ & $12.50 \pm 0.71$ & $11.00 \pm 0.00$ & $10.00 \pm 0.00$ & $9.00 \pm 0.00$ & $8.50 \pm 0.71$ & $7.00 \pm 0.00$ \\
$\boldsymbol{P .}$ aeruginosa & $10.00 \pm 0.00$ & $9.50 \pm 0.71$ & $8.00 \pm 0.00$ & $7.00 \pm 0.00$ & $7.00 \pm 0.00$ & - & - \\
K. penumoniae & $11.33 \pm 0.58$ & $10.00 \pm 0.00$ & $9.50 \pm 0.71$ & $9.00 \pm 0.00$ & $7.50 \pm 0.71$ & $7.00 \pm 0.00$ & $7.00 \pm 0.00$ \\
\hline
\end{tabular}

* (-): Diameter of inhibition zone $\leq 6 \mathrm{~mm}$

Table 4. Effect of different concentrations of chloroformic extract of $A$. wentii fungal strain on the test bacteria.

\begin{tabular}{lccccccc}
\hline \multicolumn{1}{c}{ Bacteria } & $\mathbf{1 0 0}$ & \multirow{2}{*}{$\mathbf{~} \mathbf{~ m g} / \mathbf{m l}$} & $\mathbf{2 5} \mathbf{~ m g} / \mathbf{m l}$ & $\begin{array}{c}\mathbf{1 2 . 5} \\
\mathbf{m g} / \mathbf{m l}\end{array}$ & $\begin{array}{c}\mathbf{6 . 2 5} \\
\mathbf{m g} / \mathbf{m l}\end{array}$ & $\begin{array}{c}\mathbf{3 . 1 2 5} \\
\mathbf{m g} / \mathbf{m l}\end{array}$ & $\begin{array}{c}\mathbf{1 . 5 6} \\
\mathbf{m g} / \mathbf{m l}\end{array}$ \\
\hline S. aureus & $14.00 \pm 1.41$ & $12.50 \pm 0.71$ & $12.33 \pm 0.58$ & $11.00 \pm 0.00$ & $11.00 \pm 0.00$ & $9.50 \pm 0.71$ & $7.50 \pm 0.71$ \\
B. subtilis & $14.50 \pm 2.12$ & $13.00 \pm 1.41$ & $11.50 \pm 0.71$ & $11.00 \pm 1.41$ & $10.0 \pm 0.00$ & $8.50 \pm 0.71$ & $7.00 \pm 0.00$ \\
E. faecalis & $16.50 \pm 0.71$ & $14.00 \pm 0.00$ & $13.33 \pm 0.58$ & $11.50 \pm 0.71$ & $8.00 \pm 0.00$ & $7.00 \pm 0.00$ & $7.00 \pm 0.00$ \\
$\boldsymbol{E}$ coli & $13.00 \pm 1.41$ & $11.50 \pm 0.71$ & $11.00 \pm 0.00$ & $11.00 \pm 0.00$ & $10.00 \pm 0.00$ & $8.33 \pm 0.58$ & $8.00 \pm 0.00$ \\
$\boldsymbol{P .}$ aeruginosa & $10.00 \pm 0.00$ & $9.33 \pm 0.58$ & $8.00 \pm 1.41$ & $8.00 \pm 0.00$ & $7.00 \pm 0.00$ & - & - \\
$\boldsymbol{K}$. penumoniae & $13.00 \pm 1.41$ & $10.00 \pm 00$ & $9.33 \pm 0.58$ & $9.00 \pm 0.00$ & $9.00 \pm 0.00$ & $8.00 \pm 0.00$ & $7.50 \pm 0.71$ \\
\hline
\end{tabular}

* (-): Diameter of inhibition zone $\leq 6 \mathrm{~mm}$ 


\section{CONCLUSION}

In the context of research for new antibiotic molecules, three fungal strains of Aspergillus genus were tested against six bacterial strains. The highlighting test revealed that the three fungal strains have the ability to produce antibacterial molecules. In order to optimize the extraction conditions of these bioactive molecules, five solvents with different polarities were tested, in which chloroform turned out to be the best solvent. Fermentation on different media has shown that the nature of carbon, nitrogen, and mineral sources of the culture media influences enormously the antibiotics' production capacity in fungi. Therefore, the research perspectives would consist in completing the characterization, the purification and the identification of these molecules, as well as the optimization of their biosynthesis for medical purposes.

\section{REFERENCES}

Abdelaziz W. 2006. Isolement des mycètes producteurs des substances antibactériennes à partir des sols sahsriens. UFMC.

Atoui A. 2006. Approche de la mycotoxinogenese chez Aspergillus ocbraceus et Aspergillus carbonarius: études moléculaire et physiologique. INP. Toulouse.

Atta H. M., Dabour S. M., \& Desoukey S. G. 2009. Sparsomycin antibiotic production by Streptomyces sp. AZ-NIOFDI: Taxonomy, fermentation, purification and biological activity. Journal of Agriculture and Environmental Sciences 5(3): 368-377.

Attalah M. \& Kacem Chaouche N. 1992. Production of ochratoxin A in a semisynthetic. In: The second Regional Mycoligical Conference RMC 2, Cairo. Egypt.

Al-Bayati F. A. 2008. Synergistic antibacterial activity between Thymus vulgaris and Pimpinella anisum essential oils and methanol extracts. Journal of Ethnopharmacology 116: 403-406.

Azoun S. 2016. Le, p. e. s. p. épidémiologie de la résistance bactérienne aux antibiotiques au chu de Marrakech.

Benslama O. 2014. Isolement et caractérisation des bactéries capables de dégrader l'herbicide glyphosate et optimisation des conditions de culture pour une dégradation plus efficace. UFMC.

Berdy J. 2005. Bioactive microbial metabolites. The Journal of Antibiotics 58: 1-26.

Berger Savin M. C. E. 2014. La phagothérapie : historique et potentielle utilisation contre les infections à bactéries multirésistantes, Thèse de doctorat, faculté de médecine de créteil.

Boughachiche F. 2012. Étude de molécules antibiotiques secrétées par des souches appartenant au genre Streptomyces, isolées de Sebkha. UFMC.

Boussaber E., Kadmiri I. M, Hilali L. et Hilali A. 2012. Comparaison de l'activité antimicrobienne des souches d'actinomycètes isolées de milieux variés. Science Library Editions Mersenne 4: 1-21.

Bramki A., Ghorri S., Jaouani A., Dehimat L., \& Kacem Chaouche N. 2017. Antibacterial activity of Aspergillus isolated from different Algerian ecosystems. African Journal of Biotechnology 16(32): 1699-1704.

Cavalla M. \& Eberlin, T. 1994. Isolement des streptomycetes du sol. l'opéron 19:13-17.

Gengan R. M., Chuturgoon A. A, Mulholland D. A., \& Dutton M. F. 1999. Synthesis of sterigmatocystin derivatives and their biotransformation to aflatoxins by a blocked mutant of Aspergillus parasiticus. Mycopathologia 144: 115-122

Ghorri S. 2015. Isolement des microorganismes possédant une activité anti- Fusarium. UFMC.

Guernet M. \& Hamon M. 1981. Abrégé de chimie analytique (tome 1). Masson Edition Paris: 8-12.

Gungi S., Arima K., \& Beppy T. 1983. Screening of antifungal antibiotics according to activities inducing morphological abnormalities. Agricutural and Biological Chemistry 47: 2061 2069.

Harrar A. 2012. Activités antioxydante et antimicrobienne d'extraits de Rhamnus alaternus L. UFAS.

Hasavada S. H., Thumar J. T., \& Singh S. P. 2006. Secretion of a potent antibiotic by salt-tolerant and alkaliphilic actinomycete Streptomyces sannanensis strain RJT-1. Current Science 91(10): 1393-1397.

Hazalin N. A., Ramasamy K., Lim S. M., Wahab I. A., Cole A. L., \& Abdul Majeed A. B. 2009. Cytotoxic and antibacterial activities of endophytic fungi isolated from plants at the National Park, Pahang, Malaysia. BMC Complementary and Alternative Medicine 9: 46.

Irobi O. N., Gbodi T. A., Moo-Young M., \& Anderson W. A. 2000. Antibiotic activity of Aspergillus quadrilineatus extracts isolated from a Nigerian cereal. Pharmacentical Biology 38(1): 57-60.

Kitouni M. 2007. Isolement des bactéries actinomycétales productrices d'antibiotiques à partir d'écosystèmes extrêmes. Identification moléculaire des souches actives et caractérisation préliminaire des substances élaborées. UFMC.

Kumara C. G., Mongollaa P., Josepha J., Nageswara Y. V. D., \& Kamal A. 2010. Antimicrobial activity from the extracts of fungal isolates of soil and dung samples from Kaziranga National Park, Assam, India. Journal de Mycologie Médicale 20: 283-289.

Loucif K. 2011. Recherche de substances antibactériennes à partir d'une collection de souches d'actinomycètes. caractérisation préliminaire de molécules bioactives. UFMC.

Madigan M. T. \& Martinko J. M. 2007. Biologie des microorganismes. Pearson Education France, 11e edition: 331-423, 686-718.

Madki M. A., Manzoor A. S., Powar P. V., \& Patil K. S. 2010. Isolation and biological activity of endophytic fungi from Withania Somnifera. International Journal of Pharmacy and Pharmaceutical Sciences 2: 848-858.

Maria G. L., Sridhar K. R., \& Raviraja N. S. 2005. Antimicrobial and enzyme activity of mangrove endophytic fungi of southwest coast of India. Journal of Agricultural Science and Technology 1: 67-80.

Mathan S., Subramanian V., \& Nagamony S. 2013. Optimization and antimicrobial metabolite production from endophytic fungi Aspergillus terreus KC 582297. European Journal of Experimental Biology 3(4): 138-144.

Pamel E. V., Vlaemynck G., Heyndrickx M., Herman L., Verbeken A., \& Daeseleire E. 2010. Mycotoxin production by pure fungal isolates analysed by means of an hplc-ms/ms multimycotoxin method with possible pitfalls and solutions 
for patulin-producing isolates. Mycotoxin Research 27(1): $37-$ 47.

Pandey A., Shukla A., \& Majumdar S. K. 2005. Utilization of carbon and nitrogen sources by Streptomyces kanamyceticus M27 for the production of an antibacterial antibiotic. African Journal of Biotechnology 4(9): 909-910.

Prabavathy D. \& Valli Nachiyar C. 2012. Study on the antimicrobial activity of Aspergillus sp isolated from Justicia adathoda. Indian Journal of Science and Technology 5(9): 974-6846.

Praveena Y. S. N. \& Padmini P. 2011. Antibacterial activities of mycotoxins from newly isolated filamentous fungi. International Journal of Plant, Animal and Environmental Sciences 1(1): 8-13.

Saisivam S., Bhikshapathi D. V., Krishnaveni J., \& Kishan V. 2008. Isolation of borrelidin from Streptomyces californicus-An Indian soil isolate. Indian Journal of Biotechnology 7: 349-355.

Sharma R., Sharma C. L., \& Kapoor B. 2005. Antibacterial resistance: current problems and possible solutions. Indian Journal of Medical Sciences 59: 120-129.

Tortorano A. M., Cabrini E., \& Viviani M. A. 1979. Sensibilité in vitro des levures a cinq antibiotiques. Comparaison de deux méthodes CMI en gélose et méthode des disques. Bull. Soc. Fr. Myc. Med. 8: 69-74.

Voelker F. \& Altaba S. 2001. Nitrogen source governes the pattren of grouth and pristnamycin production in Streptomyces pristinaespiralis. Microbial 147: 2447-2459.

Yamaç M. \& Bilgili F. 2006. Antimicrobial activities of fruit bodies and/or mycelial cultures of some mushroom isolates. Pharmacentical Biology 44: 660- 667. 